\title{
The Epidemiology and Etiology of Right-Sided Colonic Diverticulosis: A Review
}

\author{
Greg A. Turner ${ }^{1,2}$, Michael J. O’Grady ${ }^{1,2}$, Rachel V. Purcell ${ }^{1}$, Frank A. Frizelle ${ }^{1,2}$ \\ ${ }^{1}$ Department of Surgery, University of Otago, Christchurch; ${ }^{2}$ Colorectal Unit, Department of General Surgery, Christchurch Hospital, \\ Christchurch, New Zealand
}

\begin{abstract}
Diverticulosis of the colon is a common condition in Western countries and most patients will remain asymptomatic, but some will present with symptoms of acute diverticulitis or bleeding. Our understanding of diverticulosis is evolving but is mostly derived from diverticulosis affecting the left-sided colon. In contrast, right-sided colonic diverticulosis (RCD) is more commonly seen in Asian countries but is much less common overall. Based on the marked differences in epidemiology, it is commonly thought that these are 2 distinct disease processes. A review of the literature describing the epidemiology and etiology of RCD was performed, with a comparison to the current understanding of left-sided diverticulosis. RCD is becoming increasingly common. The epidemiology of RCD shows it to be a mostly acquired condition, and not congenital as previously thought. Many factors in the etiology of RCD are similar to that seen in left-sided diverticulosis, with a few variations. It is therefore likely that most cases of RCD represent the same disease process that is seen in the left colon.
\end{abstract}

Keywords: Diverticulum; Diverticulitis; Colon; Ascending colon; Cecum

\section{INTRODUCTION}

Diverticulosis of the colon is a common finding in the Western world. Most patients will remain asymptomatic throughout their lifetime, with the diagnosis only being made as an incidental finding at endoscopy or on cross-sectional imaging. A proportion of patients will become symptomatic with complications of diverticulosis, such as acute diverticulitis (AD) or bleeding.

The distribution of diverticula throughout the colon shows marked geographic variation. The traditional belief is that in the West it is predominantly left-sided, affecting the sigmoid colon in older patients. In contrast, Asian countries show much lower rates overall, but when diverticula are present, they often affect the right side of the colon of younger patients. Our understanding of the pathogenesis of diverticula formation has moved from being

Received: Mar 11, 2021 - Revised: May 29, 2021 - Accepted: Jun 1, 2021 Correspondence to: Greg A. Turner

Department of Surgery, University of Otago, Christchurch, PO Box 4345, Christchurch 8140, New Zealand

Tel: +64-3-364-0014, Fax: +64-3-364-0525

E-mail: Gregory.turner@cdhb.health.nz

ORCID: https://orcid.org/0000-0003-3817-173X

(C) 2021 The Korean Society of Coloproctology

This is an open-access article distributed under the terms of the Creative Commons Attribution NonCommercial License (https://creativecommons.org/licenses/by-nc/4.0) which permits unrestricted noncommercial use, distribution, and reproduction in any medium, provided the original work is properly cited. centered around the fiber hypothesis proposed by Painter and Burkitt in the 1970s [1], to be a complex interaction of genetic predisposition, connective tissue degradation, and multiple lifestyle influences [2].

The aim of this article is to review the epidemiology of rightsided colonic diverticulosis (RCD), and discuss the etiology, with reference to what is presently understood for left-sided disease.

\section{EPIDEMIOLOGY OF RIGHT-SIDED COLONIC DIVERTICULOSIS}

When considering the epidemiology of diverticulosis, 2 features dominate-geography and age [3]. The prevalence of RCD varies markedly.

As diverticulosis is asymptomatic in the majority, establishing the prevalence in a population remains challenging. The reported prevalence varies not only with the population being studied but also with the modality used for diagnosis. Cross-sectional imaging is generally considered to be more sensitive for the detection of diverticulosis than endoscopy [4]. However, such imaging is mostly performed in patients with abdominal symptoms of some description, resulting in selection bias. In contrast, colonoscopy is commonly used in asymptomatic patients for colorectal cancer screening, resulting in large datasets of asymptomatic patients, from which to estimate the prevalence. A limitation of colonos- 
copy is the potential for missing diverticula obscured by haustral folds [5]. Perhaps more importantly, since diverticulosis can be such a common finding at colonoscopy, it may be considered "normal" by the endoscopists and omitted from the procedure report. This may result in underestimation of the true prevalence in large colonoscopy datasets [6]. Regardless of the method of diagnosis, there are clear geographic differences seen in the absolute prevalence of RCD, and what proportion of diverticulosis it comprises as demonstrated in Tables 1 and 2 respectively [3-26].

\section{Western countries}

Diverticulosis is reported to be present in more than $70 \%$ of the population by the 8 th decade of life [4]; however, this is predominantly left-sided colonic diverticulosis (LCD), which accounts for over $90 \%$ of diverticulosis seen in Western countries [4, 27].

There is clearly increasing incidence with advancing age. A recent large study by Peery et al. [28] reviewed 271,181 screening colonoscopies in the United States. They found that the prevalence of diverticulosis increased with age in men and women of all ethnicities. In the 40 - to 49 -year age group, diverticulosis was identified in $27 \%$ of men and $21 \%$ of women. In the $\geq 80$-year age group, this increased to $72 \%$ for both sexes. Interestingly, they found that the higher prevalence in males was consistent across all age groups until the age of 70 years when the sex difference evens out. Given the time taken for diverticulosis to develop, they postulate that endogenous ovarian steroid hormones may be protective for diverticulosis. This study also found ethnic variation in the colonic distribution of diverticulosis. Non-Hispanic Black patients were 1.53 times more likely than White patients to have any $\mathrm{RCD}$, and 2.47 times more likely to have RCD only.

A further important finding from the Peery study [28] was the incidence of RCD with advancing age. A common misconception is that RCDs are congenital. This study analyzed the finding of RCD into subgroups of "any RCD" (i.e., patients who had RCD but may or may not have concurrent LCD) and "only RCD" (those with no LCD). Patients with only RCD did not show an increasing incidence with age, being present in only $1 \%$ of individuals aged 40 to 49 years and those aged $\geq 80$ years. In contrast, patients with any RCD had an increasing incidence with age rising from $5 \%$ in the 40 - to 49 -year age group to $16 \%$ in the over 80 s (odds ratio, 4.34; 95\% confidence interval, 3.80-4.95). These findings suggest that while a proportion of RCD is congenital, the majority are acquired and represent the same pathological process as LCD migrating proximally in the colon.

Other studies from Western populations report varying rates of diverticulosis. De Cecco et al. [18] reviewed 1,091 computed tomography (CT) colonography studies performed in Italy and found diverticulosis in $51.6 \%$ of patients overall. Diverticula were found in the cecum, ascending, and transverse colons of $9.6 \%$, $13.1 \%$, and $12.7 \%$ of patients, respectively. The prevalence of RCD again increased with age. A further Italian study reported a much lower rate of diverticulosis at $19 \%$ overall, with RCD in only $2 \%$ [19]. However, this study used colonoscopy rather than cross-sectional imaging as the diagnostic modality, and defined diverticulosis as the presence of 5 or more diverticula; and therefore, patients with few diverticula will have been underrepresented. In a study of 796 French patients undergoing colonoscopy, diverticulosis was found in 40\%; and of patients with diverticulosis, a third had RCD [14]. The overall prevalence of RCD was $25 \%$ by 75 years of age. The authors suggest that, based on their findings, the prevalence of RCD in Western countries is likely underestimated.

A result reported in Table 2 worthy of discussion is that of Meh-

Table 1. Studies reporting population prevalence of right-sided diverticulosis

\begin{tabular}{llllrrrrr}
\hline Study & Year & Country & $\begin{array}{l}\text { Diagnostic } \\
\text { Modality }\end{array}$ & Total & $\begin{array}{c}\text { Total } \\
\text { diverticulosis }\end{array}$ & Right-sided & Left-sided & Bilateral \\
\hline Kubo et al. [7] & 1983 & Japan & DCBE & 12,505 & $969(7.7)$ & $745(6.0)$ & $126(1.0)$ & $108(0.9)$ \\
Lee [8] & 1986 & Singapore & Autopsy & 1,014 & $194(19.1)$ & $141(13.9)$ & $34(3.4)$ & $19(1.9)$ \\
Nakada et al. [9] & 1995 & Japan & DCBE & 6,849 & $1,074(15.7)$ & $743(10.8)$ & $143(2.1)$ & $188(2.7)$ \\
Song et al. [10] & 2010 & Korea & Colonoscopy & 848 & $103(12.1)$ & $87(10.3)$ & $9(1.1)$ & $7(0.8)$ \\
Fong et al. [11] & 2011 & Singapore & DCBE & 1,663 & $751(45.2)$ & $597(35.9)$ & $297(17.9)$ & $169(10.2)$ \\
Nagata et al. [12] & 2013 & Japan & Colonoscopy & 2,164 & $542(25.0)$ & $271(12.5)$ & $112(5.2)$ & $159(7.3)$ \\
Lohsiriwat and Suthikeeree [13] & 2013 & Thailand & DCBE & 2,877 & $820(28.5)$ & $641(22.3)$ & $383(13.3)$ & $98(3.4)$ \\
Faucheron et al. [14] & 2013 & France & Colonoscopy & 796 & $318(39.9)$ & $103(12.9)$ & $215(27.0)$ & $63(7.9)$ \\
Nagata et al. [15] & 2014 & Japan & Colonoscopy & 28,192 & $6,150(21.8)$ & $2,861(10.1)$ & $1,470(5.2)$ & $1,631(5.8)$ \\
Tanaka et al. [16] & 2016 & Japan & Colonoscopy & 5,145 & $1,539(29.9)$ & $780(15.2)$ & $759(14.8)$ & Not stated \\
Hong et al. [17] & 2016 & China & Colonoscopy & 63,034 & $1248(2.0)$ & $1065(1.7)$ & $136(0.2)$ & $47(0.1)$ \\
Bong et al. [3] & 2020 & Korea & Colonoscopy & 1,316 & $115(8.7)$ & $105(8.0)$ & $24(1.8)$ & $14(1.1)$ \\
\hline
\end{tabular}

Values are presented as number only or number (\%).

DCBE, double-contrast barium enema. 


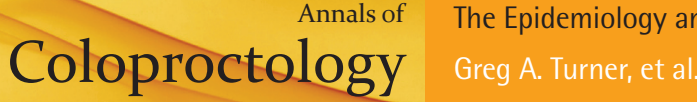

Table 2. Prevalence of right-sided diverticulosis expressed as a proportion of cases that had any diverticulosis identified

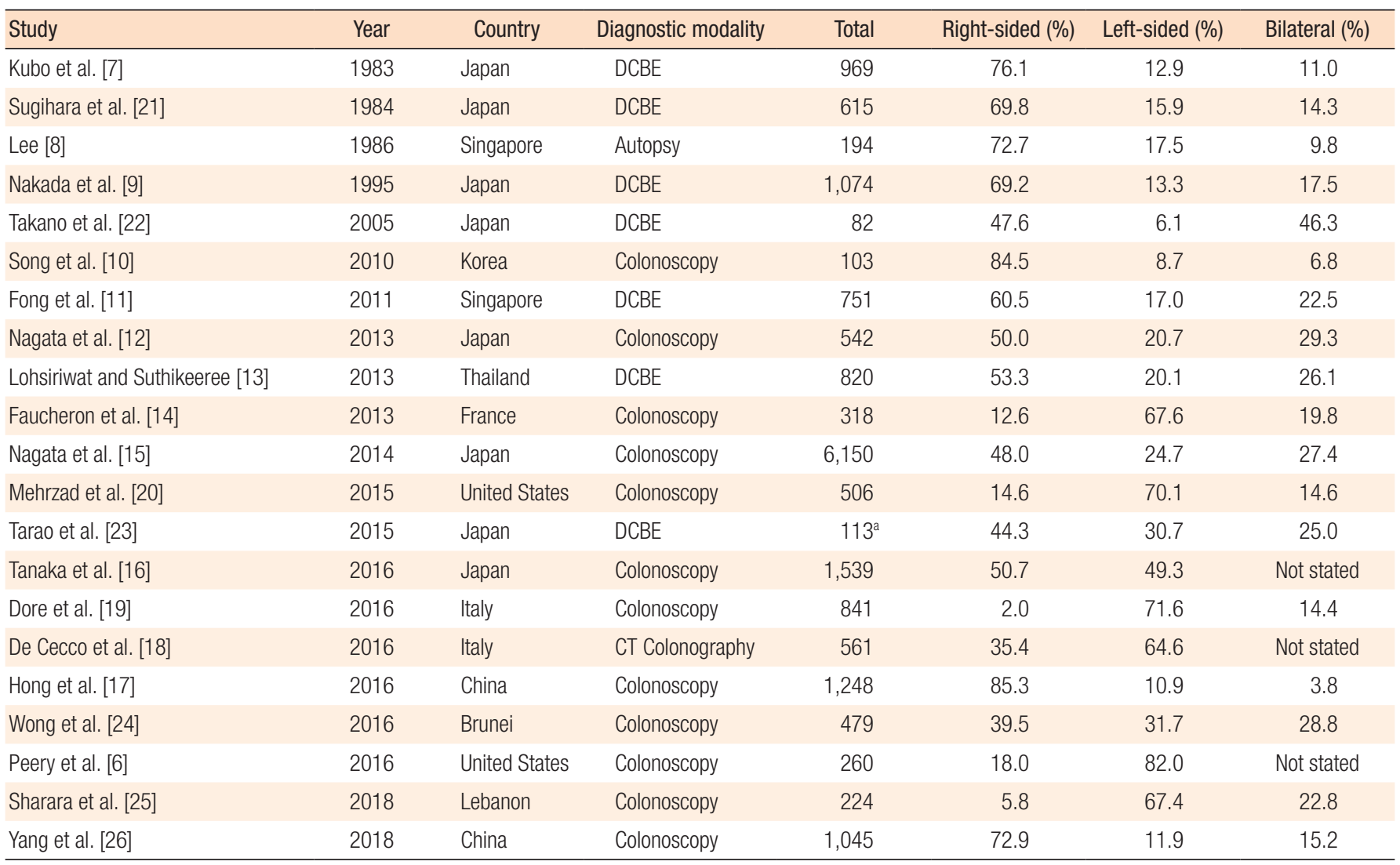

DCBE, double-contrast barium enema; CT, computed tomography.

aDistribution breakdown limited to 88 patients who had 4+ diverticula.

rzad et al. [20]. This study from American authors reviewed 207 Vietnamese patients residing in Boston having their first screening colonoscopy and compared the findings to those of 299 White patients during the same period. When limited to the 207 Vietnamese participants, the prevalence of RCD and bilateral diverticulosis was $31.1 \%$ and $18.4 \%$, respectively. In the White patients forming a control group, nearly $97 \%$ of these patients had LCD or bilateral diverticulosis, compared to only $3.0 \%$ with RCD alone.

\section{Asian countries}

The overall prevalence of diverticulosis in Asian countries is much lower than that seen in the West; however, RCD predominates. Table 1 shows the rate of $2 \%$ to $45 \%$, overall, with RCD being found in over 1/3 of patients in Singapore [11], although most Asian studies report RCD to be found in the range of $10 \%$ to $15 \%$ of individuals. When considered as a proportion of individuals with diverticulosis, the majority have right-sided or bilateral diverticula (Table 2). Similar to that seen in Western populations, the prevalence of diverticulosis has been increasing in recent years $[3,10,12,26,29]$.

\section{ETIOLOGY AND RISK FACTORS FOR RIGHT- COLONIC DIVERTICULOSIS}

\section{Right-sided diverticula: congenital or acquired?}

A diverticulum of the cecum was first described by Potier in 1912 [30]. With the tendency of RCD to affect younger patients, they are frequently considered to be congenital, solitary, and true diverticula affecting the full thickness of the bowel wall, in contrast to the acquired false diverticula seen in the distal colon. Amounting evidence demonstrates an increasing prevalence with advancing age, which contradicts this hypothesis.

Multiple studies have shown that, histologically, right-sided diverticula are a mix of true and false diverticula. Hughes [31] carried out an autopsy study in Australia where the colons from 24 patients with cecal diverticulosis had histopathological examinations. Five of these patients had primary cecal diverticula with no diverticulosis elsewhere in the colon. Microscopically, all cecal diverticula proved to be false diverticula. Similar findings were found in a Singaporean autopsy study, where 194 patients with diverticulosis had false diverticula when examined microscopically. This included 39 patients who had a solitary diverticulum [8].

Graham and Ballantyne [32] reported a large series of cecal di- 
verticulitis. Of 128 cases with histology available, $59 \%$ of cecal diverticula were false diverticula. They also found that among 288 patients, $81 \%$ of cecal diverticula were solitary and $19 \%$ multiple. A Japanese study of over 12,000 barium enemas found the opposite, with $20 \%$ of right-sided diverticula being solitary [7].

Further evidence to support RCD being an acquired condition comes from a study of 84 patients who had consecutive barium enemas at least 10 years apart, assessing the number and distribution of diverticula within the colon. It found that, initially, diverticula were predominantly on the right side, and tended to strongly increase in number on the right side as well as become bilateral over time [22].

While many textbooks still convey the theory of RCD being congenital, solitary, true diverticula, there is significant direct and epidemiological evidence to counteract this. It is most likely that RCD represents 2 distinct processes. A proportion of RCD is congenital; however, it is increasingly evident that RCD is an extension of the same process that causes LCD. Comparisons of differences in epidemiology and various etiological factors are shown in Table 3.

\section{Dietary fiber intake and the role of raised intraluminal pressure}

In the 1970s, Painter and Burkitt [1] reported diverticulosis to be a disease of Western society, based on a study that found much lower rates of diverticulosis in African populations, compared to that of the United States. This was ascribed to differences in the intake of insoluble dietary fiber influencing the development of diverticulosis. Reduced dietary fiber in Western populations results in reduced stool bulk and firmer stools; and therefore, to propel the stool distally in the colon, higher intraluminal pressure must be generated. This higher pressure results in herniation of the mucosa/submucosa through points of weakness in the muscle coat, resulting in diverticula formation.

This theory remained surgical dogma for decades, but more recently has been challenged [33]. Current understanding of the pathophysiology of diverticulosis is that it is a multifactorial process, secondary to connective tissue degeneration in a genetically susceptible individual [34].

An important factor driving the fiber hypothesis was that diverticulosis is commonly seen in the sigmoid colon, where stool is firm and the lumen is narrow. In contrast, the right colon contents are more liquid and its lumen is larger; and therefore, according to the law of Laplace, the peak wall tension generated will be lower.

An early study by Sugihara et al. [35] in Japan measured the intraluminal pressure in 13 patients with RCD compared to 10 healthy controls. At resting state, the RCD patients had greater colonic motility than controls. After administration of intravenous neostigmine, higher pressure peristaltic contractions were generated and the increase in colonic motility was exaggerated compared to the control group. They concluded that high intraluminal pressure and abnormal motility do play a role in the pathogenesis of RCD. Similar conclusions were reached by a further study with similar methodology [36].

While the evidence is accumulating disproving the Painter and Burkitt's hypothesis [1] for diverticulosis in general, data specific to the influence of dietary fiber for RCD and/or Asian populations is lacking. Bong et al. [3] from Korea performed a case-control study evaluating the influence of a vegetarian diet on the likelihood of diverticulosis at screening colonoscopy. The vegetarian group was comprised of Buddhist monks, who are obligatory lifelong vegetarians for spiritual reasons (thus avoiding recall bias or previous exposure to nonvegetarian diet), compared to a nonvegetarian control group. They found that $6.1 \%$ of Buddhist monks had RCD, which was significantly lower than the $9.9 \%$ seen in the control group. On multivariate analysis, a nonvegetarian diet remained associated with a significantly increased risk of RCD.

In contrast, Song et al. [10] found no association between dietary fiber intake and the presence of diverticulosis on screening colonoscopy in a Korean population. Likewise, Nagata et al. [37] found no association with the presence of RCD and constipation/

Table 3. Summary of epidemiological changes and various etiological factors and their relative importance in the development of right-sided colonic diverticulosis

\begin{tabular}{lll}
\hline Variable & \multicolumn{1}{c}{ Right-sided diverticulosis } & Left-sided diverticulosis \\
\hline Epidemiology & & Common \\
Prevalence & Relatively low & Increasing \\
Incidence over time & Increasing & Acquired \\
Congenital vs. acquired & Mostly acquired, some congenital & Increasingly challenged of late \\
Etiology & & ++ \\
Role of intraluminal pressure & Uncertain & ++ \\
Genetics & +++ & ++ \\
Colonic wall structural change & + & + Insufficient evidence \\
Obesity & & + \\
\hline
\end{tabular}


firm stool. Interestingly, for LCD they found a negative association between firm stool and presence of diverticulosis.

\section{Gas production by intestinal bacteria as a cause of raised intraluminal pressure}

Methane gas has been reported to delay small intestinal transit and increase intraluminal pressure, and intraluminal pressure has been hypothesized to lead to diverticulosis as described above. Methanogenic bacteria and archaea convert lactulose into methane gas, and Jang et al. [38] tested the hypothesis that methane gas production increases intraluminal pressure in the right colon, which may predispose to the development of RCD. The study performed lactulose breath testing on 30 patients with RCD, compared to 30 healthy controls. They did not find a significant difference in the rate of methane or hydrogen gas production between the 2 groups, concluding that colonic gas is unlikely to be implicated in the pathogenesis of RCD.

\section{Genetic influences are likely to be particularly important in the development of right-sided diverticulosis}

For diverticulosis in general, evidence for a genetic influence is accumulating [39]. Based on twin studies, genetic variation is thought to account for $40 \%$ to $50 \%$ of an individual's risk of diverticulosis $[40,41]$. As well as information gathered from twin studies, connective tissue disorders, such as Marfan and Ehlers-Danlos syndromes, with well-defined genetic mutations, have predisposition to diverticulosis $[39,42]$.

The role of genetic influences is likely to be even greater for RCD. Such marked variation in the prevalence of RCD between Asian and Western countries will undoubtedly be attributable to variations in lifestyle. However, even within a given geographic area, there are ethnic differences in prevalence observed, which suggests lifestyle factors do not explain all of the variations.

The Peery study described above [28] found that Asians or Pacific Islanders were more than 3 times more likely to have only RCD, with a smaller but still significantly increased risk of RCD in Black individuals, when compared to the non-Hispanic White reference population. Similarly, in a study of barium enemas performed in Singapore, all ethnicities appeared to have a similar risk of LCD, whereas ethnic Chinese patients appeared particularly susceptible to RCD [11].

Perhaps the greatest support for the genetic influence in RCD comes from the fact that Japanese people, who immigrate to Hawaii and adopt a Western lifestyle, maintain a similar pattern of $\mathrm{RCD}$ to those who remain in mainland Japan [43]. Song et al. [10] hypothesize that the higher rate of RCD seen in Asians is due to a structurally weaker right colon, possibly explained by genetic factors. Other authors support the hypothesis that genetics have a greater influence on the development of diverticulosis in Asian compared to Western populations [44].

In general, highly prevalent conditions are due to complex interactions of multiple genes, rather than a single causative mutation.
Therefore, it is unlikely that diverticulosis is attributable to a single genetic fault. Progress has, however, been made in identifying gene(s) implicated in its development. Choe et al. [45] performed a genome-wide association study of RCD in a Korean population. They performed genomic analysis on patients having comprehensive health checks, who were also undergoing screening colonoscopy, and compared genomic aberrations with the presence or absence of RCD at colonoscopy. They identified 9 single nucleotide polymorphisms, within or adjacent to 3 potential candidate genes (WNT4, RHOU, and OAS1/3 genes). These 3 genes could conceivably play a role in the development of RCD based on their known functions. WNT4 is involved in vascular smooth-muscle cell proliferation, while the $R H O U$ gene plays a role in mediating WNT signaling pathways. The OAS gene products are induced by interferon and may play a role in the mucosal response to gut bacteria and low-grade inflammation.

\section{Alterations in the enteric nervous system and structural changes within the colonic wall}

An in vitro study examining functional differences of the enteric nervous system of both right and left colons, with and without diverticulosis, subjected to selective receptor blockade, found that colons with diverticulosis showed significantly stronger cholinergic contractions compared to normal controls, regardless of laterality [46]. This suggests that cholinergic (stimulatory) nerves dominate in colons with diverticulosis, in contrast to nonadrenergic, noncholinergic nerves dominating in normal colons. These findings lend support to higher intraluminal pressure caused by colonic segmentation being present in diverticular colons. This functional result of high intraluminal pressure in colons with RCD agrees with in vivo findings originally reported in the 1980s [35].

Additional support for enteric nervous system changes comes from Hildebrand et al. [47]. They reviewed 16 ascending colons resected for diverticular disease, 7 of which had hypo- or aganglionosis, suggestive of intestinal neuronal dysplasia, which is sometimes seen in patients with chronic constipation. It was unclear, however, whether these observed changes were a primary cause or a secondary phenomenon of RCD.

Colonic wall thickening is common in LCD [2], but evidence is conflicting in RCD. Autopsy findings from a Singaporean study found that thickening of the muscular wall was not grossly apparent in RCD, but was often obvious and marked in LCD [8]. In contrast, Murayama et al. [48] examined surgical specimens with RCD, measuring the muscular wall thickness. Over half had thickening of the taenia and almost $2 / 3$ had hypertrophy of the circular muscle layer, suggesting that changes in connective tissue composition may be less important in RCD as they are in LCD.

\section{Obesity as a risk factor for right-sided diverticulosis}

Obesity is a well-defined risk factor for the development of LCD; however, data specific to RCD are few and conflicting. A Japanese 
study of 215 patients undergoing colonoscopy found patients with RCD to be significantly less likely to be obese than those who had LCD [49]. However, this study was focusing on obesity as a risk factor for developing $\mathrm{AD}$ in patients with RCD versus $\mathrm{LCD}$, and, therefore, it lacked a control group of individuals with normal colons.

Song et al. [10] found no association between BMI and RCD in 848 patients undergoing colonoscopy. In contrast, Nagata et al. [50] assessed visceral adiposity on CT for 1,445 Japanese patients undergoing colonoscopy and found that increasing abdominal adiposity area was associated with RCD, even in normal bodyweight individuals (note that this finding was also true for LCD). With the limitations in describing the prevalence of RCD, it is unsurprising that defining its association with obesity has proved challenging.

More thoroughly investigated is the influence of obesity on developing $\mathrm{AD}$ in patients with $\mathrm{RCD}$. A recent meta-analysis addressed this, finding no association between obesity and the development of right-sided $\mathrm{AD}$ among 1,252 patients across 4 studies [51].

\section{Other lifestyle factors and their risk of right-sided diverticulosis}

Like obesity, robust evidence for the influence of various lifestyle factors on the development of RCD is lacking. The role of such factors in the development of AD in patients with RCD is often better defined.

\section{Smoking}

In Western countries, with predominantly left-sided disease, smoking increases the risk of both diverticulosis and AD [52]. Smoking does not appear to significantly increase the risk of developing RCD $[3,53]$. However, the likelihood of developing right-sided $\mathrm{AD}$ is elevated in smokers [51] and may also increase the likelihood of complicated diverticulitis [54].

\section{Alcohol}

Alcohol consumption has been shown to be a risk factor for RCD in studies from Korea and Japan [10, 12], with the Japanese study [12] reporting alcohol consumption to be a risk factor for RCD, but having no association with LCD. Similarly, Sharara et al. [55] found an association with diverticulosis overall but did not perform specific analysis for the RCD subgroup.

Perhaps the best evidence for the association of alcohol intake with the development of any diverticulosis comes from the United States, where Aldoori et al. [56] examined lifestyle factors in 47,678 men. Alcohol intake showed a nonsignificant trend toward an association with diverticulosis.

\section{Dietary factors other than fiber intake}

Dietary contributors other than insoluble fiber intake have been also been considered. When adjusting for the confounding effects of obesity or fiber intake, a diet rich in red meat or fat may increase the likelihood of RCD $[10,53]$.

\section{CONCLUSION}

Diverticulosis affecting the right colon is becoming increasingly common. Historical teaching explained RCD as an uncommon congenital finding in Asian populations. Our understanding of this condition has improved, and there is increasing evidence showing it to be an extension of the more common LCD, with a few variations in its etiology. The increasing prevalence of RCD parallels that observed for LCD in recent decades. While the changes in RCD are not entirely explained by the etiological factors discussed above, it is likely the trend will continue. As the prevalence of RCD increases, its clinical manifestations such as $\mathrm{AD}$ are likely to be encountered more frequently in the coming decades.

\section{CONFLICT OF INTEREST}

No potential conflict of interest relevant to this article was reported.

\section{ACKNOWLEDGMENTS}

Turner GA and O'Grady MJ are joint recipients of the 2020 Richard Stewart Scholarship administered by the Dunedin Basic Medical Sciences Trust.

\section{REFERENCES}

1. Painter NS, Burkitt DP. Diverticular disease of the colon: a deficiency disease of Western civilization. Br Med J 1971;2:450-4.

2. Tursi A. Current and evolving concepts on the pathogenesis of diverticular disease. J Gastrointestin Liver Dis 2019;28:225-35.

3. Bong J, Kang HW, Cho H, Nam JH, Jang DK, Kim JH, et al. Vegetarianism as a protective factor for asymptomatic colonic diverticulosis in Asians: a retrospective cross-sectional and case-control study. Intest Res 2020;18:121-9.

4. Tursi A, Scarpignato C, Strate LL, Lanas A, Kruis W, Lahat A, et al. Colonic diverticular disease. Nat Rev Dis Primers 2020;6:20.

5. Niikura R, Nagata N, Shimbo T, Akiyama J, Uemura N. Colonoscopy can miss diverticula of the left colon identified by barium enema. World J Gastroenterol 2013;19:2362-7.

6. Peery AF, Keku TO, Martin CF, Eluri S, Runge T, Galanko JA, et al. Distribution and characteristics of colonic diverticula in a United States screening population. Clin Gastroenterol Hepatol 2016;14:980-5.

7. Kubo A, Ishiwata J, Maeda Y, Kida T, Yamabe K, Shimosegawa T. Clinical studies on diverticular disease of the colon. Jpn J Med 1983;22:185-9.

8. Lee YS. Diverticular disease of the large bowel in Singapore: an 
autopsy survey. Dis Colon Rectum 1986;29:330-5.

9. Nakada I, Ubukata H, Goto Y, Watanabe Y, Sato S, Tabuchi T, et al. Diverticular disease of the colon at a regional general hospital in Japan. Dis Colon Rectum 1995;38:755-9.

10. Song JH, Kim YS, Lee JH, Ok KS, Ryu SH, Lee JH, et al. Clinical characteristics of colonic diverticulosis in Korea: a prospective study. Korean J Intern Med 2010;25:140-6.

11. Fong SS, Tan EY, Foo A, Sim R, Cheong DM. The changing trend of diverticular disease in a developing nation. Colorectal Dis 2011;13:312-6.

12. Nagata N, Niikura R, Shimbo T, Kishida Y, Sekine K, Tanaka S, et al. Alcohol and smoking affect risk of uncomplicated colonic diverticulosis in Japan. PLoS One 2013;8:e81137.

13. Lohsiriwat V, Suthikeeree W. Pattern and distribution of colonic diverticulosis: analysis of 2877 barium enemas in Thailand. World J Gastroenterol 2013;19:8709-13.

14. Faucheron JL, Roblin X, Bichard P, Heluwaert F. The prevalence of right-sided colonic diverticulosis and diverticular haemorrhage. Colorectal Dis 2013;15:e266-70.

15. Nagata N, Niikura R, Aoki T, Shimbo T, Itoh T, Goda Y, et al. Increase in colonic diverticulosis and diverticular hemorrhage in an aging society: lessons from a 9-year colonoscopic study of 28,192 patients in Japan. Int J Colorectal Dis 2014;29:379-85.

16. Tanaka Y, Arai T, Uegaki S, Sasaki M, Kanazawa N, Inamatsu T. Characteristics of colonoscopic findings in the very elderly. Geriatr Gerontol Int 2016;16:1319-23.

17. Hong W, Geng W, Wang C, Dong L, Pan S, Yang X, et al. Prevalence of colonic diverticulosis in mainland China from 2004 to 2014. Sci Rep 2016;6:26237.

18. De Cecco CN, Ciolina M, Annibale B, Rengo M, Bellini D, Muscogiuri G, et al. Prevalence and distribution of colonic diverticula assessed with CT colonography (CTC). Eur Radiol 2016;26:63945.

19. Dore MP, Pes GM, Marras G, Soro S, Rocchi C, Loria MF, et al. Risk factors associated with colonic diverticulosis among patients from a defined geographic area. Tech Coloproctol 2016;20:17783.

20. Mehrzad R, Mishra S, Faller G, Memon B, Fiore J. Right-sided diverticulosis and disparities from left-sided diverticulosis in the Vietnamese population living in Boston, Mass., USA: a retrospective cohort study. Med Princ Pract 2015;24:355-61.

21. Sugihara K, Muto T, Morioka Y, Asano A, Yamamoto T. Diverticular disease of the colon in Japan: a review of 615 cases. Dis Colon Rectum 1984;27:531-7.

22. Takano M, Yamada K, Sato K. An analysis of the development of colonic diverticulosis in the Japanese. Dis Colon Rectum 2005;48: 2111-6.

23. Tarao K, Sekino Y, Nonaka T, Iida H, Inamori M, Nakajima A, et al. Recent trends in colonic diverticulosis in Yokohama City: a possibility of changing to a more Western profile. Intern Med 2015;54:2545-50.

24. Wong ER, Idris F, Chong CF, Telisinghe PU, Tan J, Chong VH.
Diverticular disease and colorectal neoplasms: association between left sided diverticular disease with colorectal cancers and right sided with colonic polyps. Asian Pac J Cancer Prev 2016;17: 2401-5.

25. Sharara AI, Ziade N, Shayto RH, Rustom LB, Chehab H, Rimmani $\mathrm{HH}$, et al. The natural history of incidental colonic diverticulosis on screening colonoscopy. Can J Gastroenterol Hepatol 2018;2018:3690202.

26. Yang F, Lin L, Jiang X, Lv H, Sun C. Increasing diverticulosis in an aging population: a colonoscopy-based study of 5 -year trends in 26463 patients in Northern China. Med Sci Monit 2018;24:282531.

27. Imaeda $\mathrm{H}$, Hibi $\mathrm{T}$. The burden of diverticular disease and its complications: west versus east. Inflamm Intest Dis 2018;3:61-8.

28. Peery AF, Keku TO, Galanko JA, Sandler RS. Sex and race disparities in diverticulosis prevalence. Clin Gastroenterol Hepatol 2020; 18:1980-6.

29. Miura S, Kodaira S, Shatari T, Nishioka M, Hosoda Y, Hisa TK. Recent trends in diverticulosis of the right colon in Japan: retrospective review in a regional hospital. Dis Colon Rectum 2000;43: 1383-9.

30. Potier F. Diverticulite et appendicite. Bull Mem Soc Anat Paris 1912;87:29-31.

31. Hughes LE. Postmortem survey of diverticular disease of the colon. I. Diverticulosis and diverticulitis. Gut 1969;10:336-44.

32. Graham SM, Ballantyne GH. Cecal diverticulitis: a review of the American experience. Dis Colon Rectum 1987;30:821-6.

33. Elisei W, Tursi A. The pathophysiology of colonic diverticulosis: inflammation versus constipation? Inflamm Intest Dis 2018;3:5560.

34. Munie ST, Nalamati SP. Epidemiology and pathophysiology of diverticular disease. Clin Colon Rectal Surg 2018;31:209-13.

35. Sugihara K, Muto T, Morioka Y. Motility study in right sided diverticular disease of the colon. Gut 1983;24:1130-4.

36. Sasaki D, Kido A, Yoshida Y. An endoscopic method to study the relationship between bowel habit and motility of the ascending and sigmoid colon. Gastrointest Endosc 1986;32:185-9.

37. Nagata N, Niikura R, Aoki T, Shimbo T, Sekine K, Okubo H, et al. Association between colonic diverticulosis and bowel symptoms: a case-control study of 1629 Asian patients. J Gastroenterol Hepatol 2015;30:1252-9.

38. Jang SI, Kim JH, Youn YH, Park H, Lee SI, Conklin JL. Relationship between intestinal gas and the development of right colonic diverticula. J Neurogastroenterol Motil 2010;16:418-23.

39. Reichert MC, Lammert F. The genetic epidemiology of diverticulosis and diverticular disease: emerging evidence. United European Gastroenterol J 2015;3:409-18.

40. Granlund J, Svensson T, Olén O, Hjern F, Pedersen NL, Magnusson PK, et al. The genetic influence on diverticular disease: a twin study. Aliment Pharmacol Ther 2012;35:1103-7.

41. Strate LL, Erichsen R, Baron JA, Mortensen J, Pedersen JK, Riis $\mathrm{AH}$, et al. Heritability and familial aggregation of diverticular dis- 
ease: a population-based study of twins and siblings. Gastroenterology 2013;144:736-42.

42. Eliashar R, Sichel JY, Biron A, Dano I. Multiple gastrointestinal complications in Marfan syndrome. Postgrad Med J 1998;74:4957.

43. Nakaji S, Danjo K, Munakata A, Sugawara K, MacAuley D, Kernohan $\mathrm{G}$, et al. Comparison of etiology of right-sided diverticula in Japan with that of left-sided diverticula in the West. Int J Colorectal Dis 2002;17:365-73.

44. Martel J, Raskin JB; NDSG. History, incidence, and epidemiology of diverticulosis. J Clin Gastroenterol 2008;42:1125-7.

45. Choe EK, Lee JE, Chung SJ, Yang SY, Kim YS, Shin ES, et al. Genome-wide association study of right-sided colonic diverticulosis in a Korean population. Sci Rep 2019;9:7360.

46. Tomita R. Are there any functional differences of the enteric nervous system between the right-sided diverticular colon and the left-sided diverticular colon?: an in vitro study. Int J Colorectal Dis 2014;29:571-7.

47. Hildebrand P, Kropp M, Stellmacher F, Roblick UJ, Bruch HP, Schwandner O. Surgery for right-sided colonic diverticulitis: results of a 10-year-observation period. Langenbecks Arch Surg 2007;392:143-7.

48. Murayama N, Baba S, Kodaira S, Abe O. An aetiological study of diverticulosis of the right colon. Aust N Z J Surg 1981;51:420-5.

49. Yamada E, Ohkubo H, Higurashi T, Sakai E, Endo H, Takahashi H, et al. Visceral obesity as a risk factor for left-sided diverticulitis in Japan: a multicenter retrospective study. Gut Liver 2013;7:532-8.
50. Nagata N, Sakamoto K, Arai T, Niikura R, Shimbo T, Shinozaki M, et al. Visceral abdominal obesity measured by computed tomography is associated with increased risk of colonic diverticulosis. J Clin Gastroenterol 2015;49:816-22.

51. Hajibandeh S, Hajibandeh S, Smart NJ, Maw A. Meta-analysis of the demographic and prognostic significance of right-sided versus left-sided acute diverticulitis. Colorectal Dis 2020:22;1908-23.

52. Aune D, Sen A, Leitzmann MF, Tonstad S, Norat T, Vatten LJ. Tobacco smoking and the risk of diverticular disease: a systematic review and meta-analysis of prospective studies. Colorectal Dis 2017;19:621-33.

53. Lin OS, Soon MS, Wu SS, Chen YY, Hwang KL, Triadafilopoulos G. Dietary habits and right-sided colonic diverticulosis. Dis Colon Rectum 2000;43:1412-8.

54. Manabe N, Haruma K, Nakajima A, Yamada M, Maruyama Y, Gushimiyagi $\mathrm{M}$, et al. Characteristics of colonic diverticulitis and factors associated with complications: a Japanese multicenter, retrospective, cross-sectional study. Dis Colon Rectum 2015;58: 1174-81.

55. Sharara AI, El-Halabi MM, Mansour NM, Malli A, Ghaith OA, Hashash JG, et al. Alcohol consumption is a risk factor for colonic diverticulosis. J Clin Gastroenterol 2013;47:420-5.

56. Aldoori WH, Giovannucci EL, Rimm EB, Wing AL, Trichopoulos DV, Willett WC. A prospective study of alcohol, smoking, caffeine, and the risk of symptomatic diverticular disease in men. Ann Epidemiol 1995;5:221-8. 